\title{
Analysis and control of multidrug-resistant bacteria in hospital
}

\author{
Aoxiang Shi*1, Lihua Sun ${ }^{2}$ \\ ${ }^{1}$ Department of Hospital Infection Management, The Third Affiliated Hospital of Inner Mongolia Medical University, Baotou, \\ China \\ ${ }^{2}$ Emergency Department, The Third Affiliated Hospital of Inner Mongolia Medical University, Baotou, China
}

Received: May 1, 2015

Accepted: July 2, 2015

Online Published: September 10, 2015

DOI: $10.14725 /$ dcc.v2n3p1

URL: http://dx.doi.org/10.14725/dcc.v2n3p1

\begin{abstract}
Objective: To investigate the status of multidrug-resistant bacteria and the prevention and control measures of nosocomial infection in our hospital.

Methods: The annual monitoring of multidrug-resistant bacteria infection was measured to summarize the bacteria species, statistical distribution and antibiotic resistance. Identification of multidrug-resistant bacteria infection in patients infected or hospital acquired infections was taken to analyze the reasons of multidrug-resistant bacteria strain and put forward the relevant measures.

Results: The top five of multidrug-resistant strains infections were: Gram-positive bacteria including methicillin-resistant Staphylococcus aureus, Staphylococcus aureus; Gram-negative bacteria including Escherichia coli, Acinetobacter baumannii, Klebsiella pneumoniae.

Conclusions: The occurrence of multidrug-resistant hospital infections could be prevented by rational use of antibiotics, hand hygiene and disinfection management, and reinforced monitoring of multidrug-resistant bacteria.
\end{abstract}

Key Words: Multidrug-resistant bacteria, Hospital infection, Prevention and control

Multidrug-resistant bacteria are the pathogenic bacteria which occur drug-resistance to three or more commonly used clinical categories (such as aminoglycoside, macrolide, $\beta$-lactams, fluoroquinolones and so on), but not three in the same class. The main reasons for the increase of resistance rate of pathogens are pharmaceutical marketization and the pursuit of economic efficiency, and irrational use and abuse of antibiotics. Multidrug resistance and drugresistant bacteria are one of the difficult clinical problems, seriously threatening the lives and health of patients. It is imperative to make corresponding prevention and control measures. In response to the request brought up by Ministry of Health on multidrug-resistant bacteria, ${ }^{[1]}$ and in order to avoid cross infection of multidrug-resistant bacteria and outbreak of nosocomial infection, the infection situations of multidrug-resistant bacteria in our hospital in 2014 were monitored and summarized to analyze the factors leading to infection and present related recommendations. The reports were as follows.

\section{Materials and methods}

\subsection{General information}

According to the annual monitoring, there were 297 inpatients and 28 outpatients infected with multidrug-resistant bacteria in our hospital, including 195 males and 130 fe-

\footnotetext{
*Correspondence: Aoxiang Shi; E-mail: 735091543@qq.com; Address: The Third Affiliated Hospital of Inner Mongolia Medical University, Baotou, China.
} 
males, aged 1-99 years. 90-99 years old infected people accounted for $3.69 \%(12 / 325)$; 80-89 years old infected people accounted for $18.46 \%(60 / 325)$; 70-79 years old infected people accounted for $32.92 \%$ (107/325); 60-69 years old infected people accounted for $18.77 \%$ (61/325); 50-59 years old infected people accounted for $7.38 \%$ (24/325); 40-49 years old infected people accounted for $10.15 \%$ (33/325); 30-39 years old infected people accounted for $4.62 \%$ (15/325); 20-29 years old infected people accounted for $2.18 \%(8 / 325)$; 0 year old infected people accounted for $1.52 \%(5 / 325)$. Average age was $66.5 \pm 12.3$ years, hospitalization time took $9-16 \mathrm{~d}$ with an average length of $12.1 \pm 0.8 \mathrm{~d}$. The clinical diagnosis includes urinary system, respiratory system, cardio- and cerebrovascular diseases and burn etc.

\subsection{Methods}

The pathogenic bacteria species, the location of infection and drug-resistance situation were analyzed by Target monitoring. The Notification of Clinical Monitoring Feedback and Prevention was issued according to the patients. The nursing staff were enjoined to strictly implement the prevention and control measures.

\section{Results}

\subsection{Nosocomial infection surveillance}

Acquired infection patients (outpatients and multidrugresistant bacteria infected patients who were collected specimens within 24 hours of admission for bacteriological examination) accounted for $71.38 \%(232 / 325)$; nosocomial infection patients accounted for $28.62 \%(93 / 325)$.

\subsection{Specimen source}

345 infectious specimens from 325 infected patients were mainly taken from urine, sputum, blood and body fluid. The proportion of urine specimens was $39.13 \%$ (135/345), and the specimens in Urinary Surgery Department accounted for $27.41 \%$ (37/135), which occupied the first place in 17 clinical departments. The proportion of sputum samples was $33.33 \%(115 / 345)$, and the highest ratio of these samples was in Respiratory Department (MICU) among 15 clinical departments, accounted for $47.83 \%$ (55/115). The proportion of blood specimens accounted for $11.01 \%$ (38/345), and Respiratory Department (MICU) again occupied the top on blood infectious specimens in 15 clinical departments, accounted for $31.58 \%(12 / 38)$. The proportion of body fluid specimens was $16.52 \%(57 / 345)$, and the infectious specimens in Burn Department were more than the other 17 clinical departments, accounted for $22.81 \%$ (13/57).

\subsection{Distribution of multidrug-resistant bacteria}

A total of 402 strains of multidrug-resistant bacteria were isolated from 325 patients, among them, 139 strains were multidrug-resistant bacteria infected in the hospital. See the distribution in Table 1.

\subsection{Drug-resistance distribution}

The drug-resistance distribution was in Tables 2 and 3.

\subsection{Death distribution}

There were 17 deaths in 325 cases of infection including 9 males and 8 females, aged 59-99 years. Among them, 1 case of 59 years old (lung cancer); 1 case of 67 years old (lung cancer); 1 case of 69 years old (leukaemia); 1 case of 77 years old; 11 cases of 80-89 years old; 1 case of 95 and 99 years old, seperately. The main diagnosis of death is senile pulmonary, and cardio- and cerebrovascular chronic diseases.

\section{Discussion}

Besides the marketization of medicine and pursuit of economic benefits, patients' purchase of antibiotics themselves and individual pharmacies and clinics abuse are also important reasons that lead to multidrug-resistant bacteria infection before patients' hospitalization. Multidrug-resistant bacteria are the main pathogens of nosocomial infection, seriously threatening the health and life safety of medical personnel (themselves and their families) and the patients; as well as an important index to measure nosocomial infection prevention and control measures and rational use of antibiotics. The elderly, children and patients with extensive deep burn require long-term hospitalization according to state of illness; they are also susceptible population due to an excess of invasive operations. Corresponding systems should be established according to the targeting multidrug-resistant bacteria characteristics of each department. It is an positive measure to control the infection of multidrug-resistant bacteria and prevent nosocomial infection, ${ }^{[2]}$ the authors hence put forward the following suggestions.

\subsection{Strengthen training and improve the system}

Multidrug-resistant bacteria management is the basis to decrease nosocomial infection. Regularly training and study should be organized for medical staff to improve their knowledge, strengthen the cognition of the multidrugresistant bacteria infection, enhance vigilance against nosocomial infection and establish corresponding preventive 
measures. Relevant regulations in conformity with the work of the hospital, and overall preventive and control measures should be established for the hospital according to Multidrug Resistant Bacteria Infection Prevention and Control Technology Handbook (test) formulated by Ministry of Health in 2011 and the hospital itself. The departments must develop their own prevention and control measures in their own conditions. For some susceptible departments, we should strengthen the management and control of multidrug resistant bacteria infection to prevent such incidents. ${ }^{[3]}$

\subsection{Strengthen surveillance}

The nosocomial infection management department is responsible for the surveillance of multidrug-resistant bacte- ria in clinical departments, observing bacterial culture results every day and making periodical statistics, giving feedback to clinical departments when discovering patients with multidrug-resistant infection, implementing the corresponding protective measures against infection cases, and preventing cross infection in hospitals. In order to reduce the occurrence of such incidents, in terms of the requirements in Medical Waste Management Ordinance, ${ }^{[4]}$ we should strictly manage the medical waste used by patients with multidrugresistant infection, wrap the waste in plastic bags in isolating room and then recycle by special personnel. Medical waste and domestic waste should be differentiated, and coordination of departments should be made to ensure the normal monitoring and control work.

Table 1: Multidrug-resistant bacteria species (MRBS), constituent ratio (CR), nosocomial infection strains (NIS) and constituent ratio $(\mathrm{CR})$

\begin{tabular}{|c|c|c|c|c|}
\hline MRBS & Strain (n) & CR (\%) & NIS (n) & CR (\%) \\
\hline Gram-positive bacterium & 108 & 26.87 & 33 & 23.74 \\
\hline - Methicillin-resistant Staphylococcus aureus (MRSA) & 40 & 9.95 & 17 & 12.23 \\
\hline - Staphylococcus aureus & 27 & 6.72 & 9 & 6.47 \\
\hline - Enterococcus faecium (group D) & 25 & 6.22 & 5 & 3.60 \\
\hline - Enterococcus faecalis (group D) & 7 & 1.74 & 2 & 1.44 \\
\hline - Streptococcus pneumoniae & 3 & 0.75 & 0 & 0 \\
\hline - Staphylococcus epidermidis & 2 & 0.50 & 0 & 0 \\
\hline - Enterococcus & 2 & 0.50 & 0 & 0 \\
\hline - Staphylococcus haemolyticus & 1 & 0.25 & 0 & 0 \\
\hline - Streptococcus viridans & 1 & 0.25 & 0 & 0 \\
\hline Gram-negative bacterium & 294 & 73.13 & 106 & 76.26 \\
\hline - Escherichia coli & 152 & 37.81 & 37 & 26.62 \\
\hline - Acinetobacter baumannii & 43 & 10.69 & 23 & 16.55 \\
\hline - Klebsiella pneumoniae & 31 & 7.71 & 17 & 12.23 \\
\hline - Enterobacter cloacae & 26 & 6.47 & 12 & 8.63 \\
\hline - Pseudomonas aeruginosa & 19 & 4.73 & 9 & 6.47 \\
\hline - Citrobacter freundii & 9 & 2.24 & 3 & 2.16 \\
\hline - Klebsiella oxytoca & 5 & 1.24 & 3 & 2.16 \\
\hline - Proteus mirabilis & 5 & 1.24 & 2 & 1.44 \\
\hline - Proteus vulgaris & 1 & 0.25 & 0 & 0 \\
\hline - Morganella morganii & 1 & 0.25 & 0 & 0 \\
\hline - Alcaligenes xylosoxidans subspecies & 1 & 0.25 & 0 & 0 \\
\hline - Providencia rettgeri & 1 & 0.25 & 0 & 0 \\
\hline
\end{tabular}

3.3 Strictly observe aseptic operation, strengthen cleaning and disinfection work

Strictly observe aseptic operation. Pay attention to hand hygiene. Wash hands before and after the contact with the patients or in aseptic operations, contact with some clean and disposable items. After some invasive operations, doctors should also pay attention to hand hygiene after removal of gloves. Cleaning and disinfection should be carried out regardless of whether there is contamination on the hands. Avoid contamination and prevent multidrug-resistant infection better. Cleaning and disinfection of the environment in hospital for the diagnosis and treatment of patients with multidrug-resistant bacteria infection should be strengthened, especially for the object surfaces in the key departments. Special wipes and other articles must be used for cleaning and disinfection. The surfaces of the object that are frequently contacted by medical personnel and patients 
should be cleaned and disinfected by appropriate disinfectant, and should be disinfected immediately when contaminated by the patients' blood or body fluids. When there is an outbreak or a suspected outbreak of multidrug-resistant bacteria infection, the frequency of cleaning and disinfection should be increased.

Table 2: Main gram positive bacteria drug-resistance distribution

\begin{tabular}{|c|c|c|c|}
\hline \multirow[b]{2}{*}{ Antibiotics } & \multicolumn{3}{|c|}{ Resistant rate (\%) } \\
\hline & $\begin{array}{l}\text { Methicillin-resistant } \\
\text { Staphylococcus aureus (MRSA) } \\
(\mathbf{n}=\mathbf{4 0})\end{array}$ & $\begin{array}{l}\text { Staphylococcus aureus } \\
(\mathbf{n}=27)\end{array}$ & $\begin{array}{l}\text { Enterococcus faecium (group D) } \\
(\mathrm{n}=25)\end{array}$ \\
\hline Penicillin G & 85.0 & 100.0 & 80.0 \\
\hline Oxacillin & 85.0 & 3.7 & 4.0 \\
\hline Ampicillin & 10.0 & 0.0 & 80.0 \\
\hline Piperacillin & 22.5 & 0.0 & 4.0 \\
\hline Cefazolin & 5.0 & 0.0 & 4.0 \\
\hline Cefoxitin & 17.5 & 0.0 & 0.0 \\
\hline Cefuroxime & 5.0 & 0.0 & 4.0 \\
\hline Ceftazidime & 12.5 & 0.0 & 0.0 \\
\hline Cefotaxime & 12.5 & 0.0 & 4.0 \\
\hline Cefatriaxone & 12.5 & 0.0 & 4.0 \\
\hline Cefepime & 10.0 & 0.0 & 4.0 \\
\hline Imipenem & 10.0 & 0.0 & 0.0 \\
\hline Meropenem & 10.0 & 0.0 & 0.0 \\
\hline Aztreonam & 2.5 & 0.0 & 4.0 \\
\hline Ciprofloxacin & 92.5 & 51.9 & 88.0 \\
\hline Moxifloxacin & 70.0 & 40.7 & 4.0 \\
\hline Levofloxacin & 15.0 & 3.7 & 20.0 \\
\hline Clindamycin & 75.0 & 96.3 & 0.0 \\
\hline Erythromycin & 80.0 & 100.0 & 4.0 \\
\hline Azithromycin & 25.0 & 18.5 & 0.0 \\
\hline Gentamicin & 75.0 & 77.8 & 88.0 (high) \\
\hline Amikacin & 12.5 & 0.0 & 0.0 \\
\hline Netilmicin & 5.0 & 0.0 & 0.0 \\
\hline Streptomycin & 0.0 & 0.0 & 64.0 (high) \\
\hline Tobramycin & 15.0 & 0.0 & 4.0 \\
\hline Tetracycline & 52.5 & 37.0 & 8.0 \\
\hline Selectrin & 52.5 & 85.2 & 8.0 \\
\hline Rifampicin & 40.0 & 11.1 & 0.0 \\
\hline Chloramphenicol & 22.5 & 33.3 & 8.0 \\
\hline Furantoin & 0.0 & 0.0 & 48.0 \\
\hline Quinupristin/Dalfopristin & 2.5 & 0.0 & 24.0 \\
\hline
\end{tabular}

\subsection{Strictly enforce segregation}

Patients with multidrug-resistant bacteria infection should be segregated in single room. Patients with the same type of multidrug-resistant bacteria can be placed in the same ward. Strictly prevent patients with multidrug-resistant bacteria infection from contacting with open wound, immunocompromised, indwelling catheter patients which could lead to cross infection. ${ }^{[5]}$ Appropriate department must be negotiated before referralling the infected patients in the first place. Segregation measures should be completed before transfer. Bedside isolation should also be carried out under the condition of no single room isolation. Medical personnel should use gloves in the course of diagnosis, treatment and nursing on such patients. When contacting wounds, mu- 
cous membranes, blood, ulcerated surfaces, drainage fluid isolation clothes if necessary. ${ }^{[6]}$

and body fluids, faeces, etc., they should be careful and wear

Table 3: Main gram negative bacteria drug-resistance distribution

\begin{tabular}{|c|c|c|c|c|}
\hline \multirow[b]{2}{*}{ Antibiotics } & \multicolumn{4}{|c|}{ Resistant rate (\%) } \\
\hline & $\begin{array}{l}\text { Escherichia coli } \\
(\mathrm{n}=152)\end{array}$ & $\begin{array}{l}\text { Acinetobacter baumannii } \\
(n=43)\end{array}$ & $\begin{array}{l}\text { Klebsiella pneumonia } \\
(\mathrm{n}=31)\end{array}$ & $\begin{array}{l}\text { Enterobacter cloacae } \\
(\mathrm{n}=26)\end{array}$ \\
\hline Ampicillin & 97.4 & 11.6 & 77.4 & 100.0 \\
\hline Piperacillin & 90.1 & 100.0 & 100.0 & 96.2 \\
\hline Piperacillin/Tazobactam & 3.9 & 74.4 & 25.8 & 26.9 \\
\hline Cefazolin & 84.2 & 4.7 & 58.1 & 84.6 \\
\hline Cefoxitin & 16.4 & 7.0 & 12.9 & 84.6 \\
\hline Cefuroxime & 88.8 & 7.0 & 71.0 & 88.5 \\
\hline Cefoperazone & 15.1 & 9.3 & 12.9 & 61.5 \\
\hline Ceftazidime & 41.4 & 95.3 & 54.8 & 80.8 \\
\hline Ceftriaxone & 82.2 & 76.7 & 90.3 & 96.2 \\
\hline Cefotaxime & 81.6 & 79.1 & 90.3 & 92.3 \\
\hline Cefepime & 27.0 & 88.4 & 54.8 & 34.6 \\
\hline Imipenem & 5.3 & 67.4 & 35.5 & 0.0 \\
\hline Meropenem & 5.3 & 69.8 & 35.5 & 0.0 \\
\hline Aztreonam & 47.4 & 9.3 & 45.2 & 92.3 \\
\hline Ciprofloxacin & 94.1 & 100.0 & 87.1 & 69.2 \\
\hline Levofloxacin & 94.1 & 100.0 & 87.1 & 65.4 \\
\hline Gentamicin & 82.9 & 100.0 & 100.0 & 76.9 \\
\hline Tobramycin & 75.0 & 100.0 & 100.0 & 69.2 \\
\hline Amikacin & 12.5 & 95.3 & 32.3 & 34.6 \\
\hline Netilmicin & 28.3 & 4.7 & 19.4 & 53.8 \\
\hline Selectrin & 56.6 & 39.5 & 61.3 & 80.8 \\
\hline Furadantin & 7.9 & 2.3 & 16.1 & 30.8 \\
\hline
\end{tabular}

\subsection{Rational use of antibiotics}

Sensitive antibiotics should be selected for treatment except for special cases. Fix reasonable time to use drug according to the half-life period of the drug, and ensure the efficiency by dispensing in time, preventing abuse of antibiotics. ${ }^{[7]}$ Hospitals should conscientiously implement the relevant provisions of the rational use of antibiotics in clinical practice, strictly enforce the basic principles of clinical use of antibiotics, effectively implement the classified management of antibiotics, properly and rationally implement individualized drug delivery scheme, choose antibiotics appropriately according to clinical microbiological examination results, strictly enforce the relevant provisions of perioperative prophylactic use of antibiotics; establish and improve the clinical antibiotic prescription examination and verification system, provide up-to-date antibiotic sensitivity reports and trend analysis to clinicians regularly, correctly guide the rational use of antibiotics in clinic, avoid the occurrence of multidrug resistant bacteria due to improper use of antibiotics.

In conclusion, drug-resistant bacteria are becoming more and more serious, and the value of infection prevention is particularly important. Therefore, the prevention and control of multidrug-resistant bacteria infection is one of the most important tasks of nosocomial infection control. Monitoring must be done all the time to resolutely reduce occurrence of such incidents and put an end to it as far as possible. The process monitoring of nosocomial infection is more important than the result monitoring!

\section{Conflicts of Interest Disclosure}

The authors have no conflict of interest related to this article.

\section{References}

[1] Ministry of Health, PRC. Multidrug Resistant Bacteria Infection Prevention and Control Handbook. Beijing: Ministry of Health,
PRC; 2011.34 p.

[2] Hu BJ, Lu Q, Liu B. Strategies for improving hand hygiene compliance. Shanghai: Shanghai science and Technology Press; 2012. 20 p. 
[3] Zhang JP, Dong J, Liu Y, et al. Analysis and Nursing Countermeasures of Multidrug Resistant Bacteria Infection Patients in Department of Respiratory Medicine. Chinese Nosocomial Infection Management Journal. 2012; 22(15): 3250.

[4] Yao R, Cao SZ. Modern Nosocomial Infection Management and Control. Contemporary medicine. 2010; 16(2): 45-47.

[5] Liang YL, Guan AM. Strengthen Nursing Management and Control Nosocomial Infection. Contemporary Medicine. 2011; 17(16):
23-25.

[6] Xu HH, Liu YX, Huang WF. Strengthen the Effect of Nursing Management to Prevent Hospital Infection. Journal of Qilu Nursing. 2012; 18(3): 89-90.

[7] Bellone A, Lascio HR. Chest physical therapy in patients which acute ex-acerbarion of chronic bronchitis: effectiveness of three methods. Arch phys Med Rehabil. 2000; 81(5): 558-560. https: //doi.org/10.1016/S0003-9993(00)90034-0 c 